\title{
Governança Global na Amazônia: o Programa Piloto para a Proteção das Florestas Tropicais do Brasil
}

\section{Global Governance in the Amazon: the case of the Program Pilot for the Protection of Tropical Forests in Brazil}

Alberto Teixeira da Silva - Doutor em Ciências Sociais pela Unicamp; Professor Associado do Instituto de Filosofia e Ciências Humanas da UFPA. E-mail: alberts@ufpa.br

\section{Resumo}

A Amazônia deixou de ser apenas uma questão regional e nacional, tornandose decisivamente uma questão global. Envolta nas contradições do capitalismo global, tornou-se, ainda alvo de interesses e pressões externas, notadamente pelos recursos estratégicos e vitais que dispõe para a segurança planetária. O Programa Piloto para a Proteção das Florestas Tropicais do Brasil (PPG-7) surge como caso emblemático de inserção da Amazônia num esforço de governança global, processo esse orientado por uma multiplicidade de atores, coalizões e estratégias. Neste sentido, oriundo das lutas socioambientalistas, no plano da sociedade civil brasileira e dos movimentos transnacionais, o PPG-7 foi um componente importante de redefinição das políticas ambientais no Brasil, alargando a esfera pública e contribuindo para a germinação de uma sociedade civil global conectada por redes na Amazônia.

\begin{abstract}
The Amazon region stopped being just a regional and national subject turning actually a global subject. Wrapped up in the contradictions of the global capitalism, it became objective of external pressures and interests, especially for the strategic and vital resources that it disposes for the planetary safety. The Pilot Program to Conserve the Brazilian Rain Forest (PPG-7) appears as an emblematic case of insertion of the Amazonian region in an effort of global governance, and this process is guided by a multiplicity of actors, coalitions and strategies. In this way, originated from the social and environmental engagement in the plan of the Brazilian civil society and from the transnational movements, PPG-7 is an important component to the new definition of the environmental politics in Brazil, enlarging the public system and contributing to the germination of a global civil society connected by networks in the Amazonian region.
\end{abstract}

\section{Keywords}

Amazon region. Sustainable development. Globalization. Global governance.
Amazônia. Desenvolvimento sustentável. Globalização. Governança global. 


\section{INTRODUÇÃO}

Um dos grandes desafios para a compreensão da Amazônica contemporânea é refletir suas vias de desenvolvimento e perspectivas no cenário das transformações tencionadas pelas demandas políticas, econômicas, sociais e ecológicas num mundo cada vez mais globalizado e interdependente. Essa percepção implica uma visão holística e abrangente de uma problemática que deixou de ser somente regional e nacional, tornando-se efetivamente de caráter global. A Amazônia é plural e complexa para ser decifrada com uma única 'chave-mestra', diante dos sistemas dinâmicos que circundam e envolvem diferentes e díspares realidades e lógicas (OLIVEIRA, 1994). Essa realidade apresenta-se multidimensional, expressando a crise da modernização capitalista e as possibilidades de transição para um novo modelo de desenvolvimento fundado no ideário da sustentabilidade (SILVA, 1997; STROH, 1998).

Ao contrário de noções correntes e ilusórias, como 'vazio demográfico', ‘pulmão do mundo e natureza intocada' - mistificações e reducionismos já tão criticados (AB'SABER, 1992; BENCHIMOL, 1992; KITAMURA, 1994; GONÇALVES, 2001), a Amazônia faz parte da história da penetração do capitalismo na fronteira, com sua lógica de dominação imanente, que através da modernização conservadora, fomentada pelo crédito e incentivos fiscais, moldou o processo de desenvolvimento regional, facilitando a entrada de capital especulativo, desenfreando uma disputa pela posse da terra, acirrando conflitos e contradições em áreas rurais e urbanas e, fundamentalmente, estabeleceu uma abissal desigualdade na apropriação do espaço econômico, político e socioambiental da região.

Contudo, pela sua privilegiada geografia, estruturas geológicas, diversidade cultural de suas populações e detentora de inestimável patrimônio de florestas (sociobiodiversidade), recantos ecoturísticos, jazidas minerais e mananciais de água doce: bens absolutamente vitais na aurora do novo milênio - commodities do futuro; a maior fronteira de recursos naturais do planeta - um megabioma que desafia saberes tradicionais e o conhecimento científico, diante das potencialidades e serviços que pode disponibilizar, como biotecnologia, sequestro de carbono, ciclos hidroquímicos, dentre outros (FEARNSIDE, 1996; KITAMURA, 1997), a Amazônia tem uma importância fundamental na gestação de um novo modelo de civilização - com a utilização racional de sua biomassa, conciliando o desenvolvimento socioeconômico com a proteção do meio ambiente no plano local, regional, nacional e global. 
Este trabalho busca refletir a inserção da Amazônia na agenda da governança global (global governance) ${ }^{1}$, tendo como exemplo o Programa Piloto para Proteção das florestas Tropicais do Brasil (PPG-7). A transição do século XX para o século XXI marca um período de profundas transformações e demandas de mecanismos de regulação no interior do sistema de gestão do meio ambiente internacional, que tem se expandido, sobretudo nas últimas décadas. A Amazônia brasileira, por sua dimensão territorial e posição diferenciada que ocupa no cenário geopolítico da América do Sul, tornou-se centro das atenções da política internacional, notadamente pelos riscos eminentes que a destruição da maior floresta do mundo poderia acarretar ao equilíbrio global.

Marco emblemático da cooperação internacional na região, pelo formato inovador de cooperação entre governos, sociedade civil e comunidade financeira internacional, o PPG-7 representou um esforço transnacional na tentativa de mitigar os efeitos perversos da pilhagem do capitalismo global. ${ }^{2}$ Vale informar que o PPG-7 foi encerrado em 2009, pelo Ministério do Meio Ambiente, sendo incorporado nas diversas políticas públicas pelos programas do governo brasileiro.

Sob forte impacto da opinião pública internacional, catalisada pela Mídia (que mostrava insistentemente cenas de destruição das florestas amazônicas), animada por imagens de satélites e pelas sistemáticas denúncias das ONGs Ambientalistas do Norte, a reunião de Cúpula do G-7 (Alemanha, Canadá, Estados Unidos, França, Itália, Japão e Reino Unido) realizada em Houston, em julho de 1990, começou a desenhar as linhas de ação transnacional em relação à Amazônia, incorporando em sua declaração final várias considerações e compromissos sobre o tema das florestas. ${ }^{3}$

\footnotetext{
Expressão bastante controversa na literatura internacional e, ainda, por incorporar-se ao vocabulário da língua portuguesa, governança constitui o desafio essencial para a gestão do presente e do futuro da humanidade. Seu alcance abrange do micro ao macro (povoados, municipalidades, cidades, estruturas nacionais, transnacionais e planetárias). Governança global não significa governo mundial, mas uma ação coletiva envolvendo múltiplos atores com a finalidade de gerir problemas comuns, que melhorem as condições de vida no planeta. Dentre as iniciativas mundiais está a Agenda 21 e a Nossa Comunidade Global (Our global neighbourbood, 1995).

2 Outras iniciativas também se orientam nesta direção, como o Programa Nacional de Meio Ambiente (PNMA), Experimento de Grande Escala Biosfera-Atmosfera (LBA - The Large Scale Biosfere-Atmosphere Experiment in Amazônia), Fundo para o Meio Ambiente Global (GEF - Global Environment Facility), além do envolvimento de Universidades e instituições externas com o propósito de alocar recursos humanos e tecnológicos para promover o desenvolvimento sustentável na região. Acrescente-se também a mobilização de movimentos ativistas transnacionais, como o Greenpeace, Fundo mundial para a natureza (WWF - World Wildlife Fund), Conservation International (CI), Friends of the Earth (FOE), dentre um número expressivo de ONGs e redes da sociedade civil - do local ao global.

3 Na ocasião, foi adotada a "Declaração Econômica de Houston", que estabelecia um diálogo em prol da cooperação norte-sul na área ambiental.
} 
Depois de um longo e tenso processo de negociação, com várias fraturas e contradições na posição dos atores governamentais nacionais e uma intensa mobilização dos segmentos da sociedade civil regional, nacional e internacional; através do decreto $n^{\circ} 563$, de 5 de junho de 1992, o governo brasileiro institui o Programa Piloto das Florestas Tropicais do Brasil, criando, ao mesmo tempo, uma Comissão de Coordenação. Embora anunciado em 1990 e oficialmente lançado em 1992, seus primeiros passos programáticos efetivamente se deram a partir de 1994, sendo que níveis expressivos de desembolso, oriundos das doações compromissadas (cerca de US\$200 milhões, em sua maioria da Alemanha, União Europeia e Reino Unido), somente foram atingidos em $1997 .{ }^{4}$

Discutimos aqui alguns dos fatores principais e condicionantes históricos que colocaram a região como alvo da preposição dessa cooperação internacional, a saber: a) o crescente consenso científico sobre problemas ambientais globais e seus efeitos sobre a Amazônia; b) a expansão do socioambientalismo na Amazônia; c) as mudanças sociais e institucionais que culminaram com a constituição de 1988, como parte da conjuntura preparatória para a realização da Conferência do Rio; d) os Estados Nacionais frente à (in)segurança ambiental planetária.

\section{CRESCENTE CONSENSO CIENTÍFICO SOBRE A PROBLEMÁTICA AMBIENTAL GLOBAL E SEUS EFEITOS SOBRE A AMAZÔNIA}

A consolidação de um consenso mundial sobre a problemática ambiental em escala global e o reconhecimento da importância estratégica da Amazônia na intensificação de alguns fenômenos mais visíveis, notadamente em relação às mudanças climáticas e perda de biodiversidade, constituiu aspectos relevantes para a inserção de mecanismos de regulação no eixo da cooperação Norte-Sul. Com efeito, para a tomada de decisão política nas questões relativas ao meio ambiente, tem sido muito frequente a manifestação da comunidade científica, como parte interessada na demonstração de evidências e indícios que efetivamente confirmem ou não os fenômenos da natureza e suas interações com o homem.

Na década de 1970, com a internalização da questão ambiental na pauta política de países europeus, sobretudo da Europa Ocidental (Alemanha, França, Inglaterra), foi se fortalecendo uma base científica, no sentido de dar suporte às decisões governamentais e às ações iniciativas da sociedade civil. Todavia, é a partir da década de 1980, que a dinâmica do sistema mundial vai ser alterada, com evidências e teses científicas sobre a emergência de problemas ambientais globais.

4 Relatório final da revisão da estrutura institucional, 1999. 
A descoberta do buraco da camada de ozônio, na Antártida (1983), constitui-se na primeira e clara manifestação de um problema ambiental transnacional ou, pelo menos, foi o primeiro a ser seriamente levado em consideração (LIPIETZ, 1997, p. 148).

Neste período, vieram à tona descobertas sobre a importância da diversidade biológica na sustentação da vida planetária. A Biodiversidade, hoje, no contexto das revoluções científicas e dos grandes negócios que envolvem uma riqueza estocada de patrimônio genético, é uma questão absolutamente decisiva para o futuro da pesquisa científica e do progresso humano. A biotecnologia, como setor de ponta das novas tecnologias no aproveitamento dos tesouros da floresta - os descobertos e os ainda por serem descobertos, movimenta bilhões de dólares nas poderosas indústrias de produtos biotecnológicos, ligando o saber científico ao saber tradicional.

"Neste campo, a ironia da história une as duas pontas de linha do tempo: em um dos extremos, os laboratórios mais avançados que a ciência já desenvolveu e, no outro, os conhecimentos das populações tradicionais, que permitem a identificação dos princípios ativos escondidos na complexidade dos ecossistemas tropicais" (CAPOBIANCO, 2002, p. 122).

$\mathrm{O}$ aquecimento global começa a ser relacionado mais diretamente com o padrão de produção e consumo das economias desenvolvidas. As emissões de gases causadores do efeito estufa indicavam um contexto de preocupações crescentes com o clima global. É absolutamente necessário desmistificar ideias e pensamentos visionários produzidos sobre a Amazônia, para que se estabeleça um diagnóstico preciso das raízes, potencialidades e limites dessa imensa e complexa região, permitindo construir cenários realistas para a implementação de um modelo de desenvolvimento sustentável. Essa é uma tarefa ingrata e urgente, pois demanda um esforço coletivo da comunidade científica local, nacional e internacional e implica no reconhecimento da grandiosidade do saber das populações tradicionais, ou seja, potencializar investimentos em ciência, tecnologia, pesquisas socioantropológicas e aprimoramento dos mecanismos de participação política.

É evidente que não se pode arrancar o pensamento mitológico secular que está ligado às formações culturais dos povos que habitam a Amazônia, ao contrário, a representação social através da narrativa mitológica reforça o papel e a riqueza da sociobiodiversidade na região. De outro modo, a Amazônia possui a marca da diversidade, o que significa dizer que constitui um espaço heterogêneo, não linear, apresentando parâmetros diferenciáveis de análises e mensurações. A perspectiva de homogeneidade dos ecossistemas regionais foi substituída por uma visão que incorpora a imensa diversidade regional. A complexidade da Amazônia é um dos 
grandes desafios da ciência e do progresso humano, tendo em vista o potencial de riquezas a serem descobertas e a utilização futura dos recursos provenientes de pesquisas e do saber histórico acumulado dos chamados "povos da floresta".

É preciso desmistificar outra categoria de fenômenos, aqueles que efetivamente obscurecem e falseiam, do ponto de vista científico e ideológico, uma interpretação moderna sobre a região. Um dos mitos mais conhecidos evoca a região como "pulmão do mundo", que teria a capacidade de garantir oxigênio para a atmosfera. Na verdade, todo oxigênio produzido é imediatamente absolvido pela floresta. Todavia, embora a floresta amazônica não seja fonte de oxigênio, é um grande reservatório de carbono. Segundo pesquisas, as florestas na Amazônia legal estocam aproximadamente 60 bilhões de toneladas de carbono em sua biomassa, correspondendo cerca de $8 \%$ da quantidade de carbono presente na atmosfera sob a forma de gás carbônico (SCHUBART, 1991, p.13-14).

No entanto, curiosamente, foi através do mito do "pulmão do mundo" que se reconheceu um grande potencial de serviços que a floresta pode oferecer (LEITE, 2001). Hoje, não se tem a menor dúvida, de que as florestas representam um sumidouro de carbono; daí o perigo crescente dos desmatamentos, que além de influenciar nas mudanças climáticas, provocam a perda considerável de biodiversidade.

Sem dúvida, o desflorestamento amazônico é uma questão delicada do ponto de vista da posição brasileira nos compromissos assumidos na Convenção do Clima e do Protocolo de Kyoto, visto que o país é considerado um modesto emissor de carbono, contribuindo com $1 \%$ das emissões mundiais, o que o coloca no $20^{\circ}$ lugar entre os emissores. Todavia, o desmatamento da Amazônia leva à emissão de cerca de 140 milhões de toneladas de carbono por ano. Somando este número aos 70 milhões de toneladas que o restante do país emite, o Brasil passa a ser o sexto emissor mundial de carbono, logo abaixo de Estados Unidos, China, ex-União Soviética, Japão e Índia. ${ }^{5}$

\section{A EXPANSÃO DO MOVIMENTO SOCIOAMBIENTALISTA NA AMAZÔNIA}

O modelo de ocupação desordenada e caótica na Amazônia, e o rastro de destruição socioambiental foi intensamente questionado e sofreu forte resistência por parte das organizações de direitos humanos, sindicais e trabalhadores rurais,

5 GOldemberg, J. Amazônia e o Protocolo de Kyoto. O Estado de São Paulo, São Paulo, 13 abr. 2001. 
sobretudo a partir da década de 1970, quando a sociedade civil foi conseguindo estabelecer formas de lutas políticas e atuações marcantes na defesa dos interesses populares, notadamente sobre a questão fundiária, indígena e socioambiental, apesar da presença autoritária do Estado brasileiro, via integração territorial a qualquer custo, ou seja, a expansão da fronteira sob a lógica capitalista.

Mas foi no início da década de 1980, com a disseminação de uma consciência socioambiental gradual e progressiva, permeando mentalidades, coletividades e estruturas, que emerge uma vitalidade de grupos e organizações inicialmente ambientalistas, que paulatinamente vão articulando um movimento mais plural e comprometido com os diversos vetores da sustentabilidade regional.

A partir da segunda metade da década de 1980, as campanhas e protestos se intensificam, tendo lado a lado organizações não governamentais brasileiras e internacionais de proteção ambiental e direitos humanos, no front das acusações relativas ao papel estratégico do Banco Mundial e de outros organismos multilaterais como fomentadores do modelo desenvolvimentista.

Sobem ao palco novos movimentos socioambientais, em que a figura de Chico Mendes e suas ideias expressam uma verdadeira revolução na produção do espaço e gestão de um desenvolvimento alternativo - um modelo de desenvolvimento baseado no aproveitamento racional dos recursos naturais, na identificação e equilíbrio entre o homem e a natureza - as reservas extrativistas ${ }^{6}$ vão se colocar frontalmente com o movimento de expansão agropecuária, que tinha nos desmatamentos e perdas de florestas o meio indispensável para a realização de seus propósitos.

A figura carismática e emblemática de Chico Mendes, como líder do movimento dos seringueiros da Amazônia, confrontou-se por meio de embates ${ }^{7}$ e denunciando o processo expansivo das fazendas de gado, que promoviam derrubadas de florestas em nome do 'progresso' e coloca-se como a principal voz com visibilidade política em defesa dos povos da floresta, aliança que vingaria mais tarde entre seringueiros, ribeirinhos e índios. Em março de 1987, Chico Mendes, como representante do Conselho Nacional dos Seringueiros (CNS), criado em 1985, foi a Washington (USA) para protestar contra o financiamento da ampliação da BR-364 para Rio Branco (AC). A principal reivindicação era

${ }_{6}$ A proposta de reservas extrativistas inaugura uma nova concepção de propriedade e gestão de recursos naturais no Brasil, em que uma determinada área demarcada passa a ser de propriedade da União, com direito de uso por parte das populações que habitam a região, por meio de um plano de uso gerido pela comunidade sob jurisdição do Ibama. Além das reservas extrativistas estaduais e federais, outras unidades de conservação representam este avanço: a Reserva de Desenvolvimento Sustentável Mamirauá, Parque Nacional do Jaú, Floresta Nacional do Tapajós, dentre outras.

Forma de resistência utilizada pelos seringueiros para impedir a derrubada da floresta. 
a de que a estrada só deveria ser ampliada se fosse garantido que o desastre de Rondônia não se repetiria. ${ }^{8}$

No mesmo ano, o Banco Interamericano de Desenvolvimento (BID) suspendeu o pagamento dos recursos para a construção da estrada. Chico Mendes, pelo trabalho incansável em prol da defesa da floresta, recebeu o Prêmio Meio Ambiente das Nações Unidas (Global 500). "Foi essa internacionalização/ mundialização/globalização que lhes permitiu sair das sombras da floresta, e por meio de suas organizações locais-regionais-nacionais, ganhar um lugar ao sol" (GONÇALVES, 2001a, p.189).

Quando Chico Mendes foi assassinado, no Acre, em dezembro de 1988, por grandes proprietários rurais, provocou uma intensa onda de protestos em todo o mundo. Certamente a sua vida não foi em vão. A sua morte significou uma inflexão decisiva nos rumos da Amazônia, sinalizando para um possível modelo de desenvolvimento sustentável baseado no aproveitamento racional e igualitário dos produtos da floresta. Mas, até que ponto pode se considerar viável esta alternativa de desenvolvimento regional, considerando os desafios de agregação de valor e geração de renda em nichos de mercados competitivos? Ao que tudo indica, a criação de reservas extrativistas representou uma oportunidade concreta de inserção das populações amazônicas na construção dos alicerces de uma sociedade sustentável.

Por outro lado, neste processo de aglutinação dos segmentos marginalizados das políticas públicas na Amazônia, os movimentos indígenas - no bojo das lutas e organização dos movimentos sociais e ambientalistas, vão expressar uma problemática de grande visibilidade política, sobretudo no contexto internacional, buscando se inserir no eixo do discurso ambiental.

Nos anos 80, os povos indígenas conseguiram articular melhor os seus interesses. Formaram organizações próprias, como por exemplo, a UNI (União Nacional Indígena), e participaram ativamente das discussões sobre a nova Constituição de 1988. Da situação de "protegidos" de um Estado que lhes negava direitos e não os reconhecia como sujeitos portadores de direitos, surgiu um vigoroso ator político na cena nacional. A nova Constituição, apesar de algumas limitações, melhorou sensivelmente a condição indígena, sobretudo no que tange à demarcação de suas terras. Depois de uma longa pressão nacional e internacional,

8 O asfaltamento da BR-364, que interligava Porto Velho (RO) à rede rodoviária nacional, dentro do Programa Polo Noroeste, que tinha um volume de recursos na ordem de US \$ 1,6 bilhões, dos quais o Banco Mundial contribuiu com US 457 milhões, provocou uma forte migração. Depois do asfaltamento, entre 1984 e 1986, Rondônia recebeu cerca de 160 mil pessoas por ano; a área desmatada aumentou de 3\% em 1980 para 17,1\% em 1988, de acordo com estimativas conservadoras (ver ARNT; SCHWARTZMAN, 1992). 
o governo brasileiro viu-se obrigado a acabar com a invasão dos garimpeiros na área do maior povo indígena da Amazônia: os Yanomamis.

As populações indígenas foram várias vezes 'vencidas' no trajeto regional de desenvolvimento capitalista. Mesmo assim, a dimensão política da questão étnica agrega-se às demais contradições desse desenvolvimento, rompe as barreiras culturais das nacionalidades e irrompe na sociedade global com muita força persuasiva. A luta pela demarcação de terras ganha simpatia da cidadania mundial e a adesão explicita de blocos, entidades e instituições influentes nas relações de poder da ordem global.

A realização do $1^{\circ}$ Encontro dos Povos Indígenas do Xingu, em fevereiro de 1989, na cidade de Altamira - estado do Pará assinala um momento de grande repercussão nacional e internacional, num período onde fluíam denúncias e protestos contra a construção do complexo hidrelétrico do Xingu. Patrocinado pelos Kaiapó, esse encontro contou com a participação de 650 índios de diversas partes do país e de fora, 300 ambientalistas, 150 jornalistas, autoridades do executivo e legislativo federal, dentre eles o então presidente da Eletronorte, José Antonio Muniz Lopes, o presidente na época do Ibama, Fernando César Mesquita, além do cantor inglês Sting. ${ }^{\text {? }}$

O encontro de Altamira contribuiu para consolidar ainda mais o socioambientalismo emergente na Amazônia. Com efeito, as lutas de índios e seringueiros foram apoiadas por várias ONGs nacionais e internacionais, que sob essas bandeiras, tiveram uma expansão crescente na agenda do socioambientalismo amazônico e ganharam respaldo, sobretudo da comunidade internacional.

\section{MUDANÇAS COM A CONSTITUIÇÃO DE 1988 E O CLIMA DE PREPARAÇÃO PARA A ECO-92}

A construção da ordem constitucional moderna brasileira, que se cristalizou na Carta de 1988, faz parte da evolução de um arcabouço jurídico-institucional, que vem desde a década de 1980. A Constituição de 1988 representou um momento da política nacional em que foi possível avançar em pontos inovadores para uma nova ordem democrática. As conquistas advindas foram saudadas com um forte otimismo, no que tange, sobretudo, à consolidação de uma legislação ambiental, no bojo das conquistas saudáveis de cidadania expressa na garantia dos direitos sociais, mecanismos de descentralização político-administrativa e canais de participação popular, nos diferentes campos de atuação das políticas públicas.

9 Mais detalhes, ver o site: http://www.socioambiental.org/website/especiais/bm/hist.asp 
A Constituição de 1988 foi um momento de incorporação de várias demandas da sociedade brasileira, abrindo espaço de reivindicação para vários grupos sociais. Assim, a partir de identidades, direitos e estratégias é possível se chegar às várias cidadanias da Constituição (CAUBET, 1989). Os Estados e Municípios adquirem uma base legal para a formulação e execução de suas políticas, estabelecendo um novo vínculo com a União. O texto constitucional dedica uma parte específica sobre o meio ambiente, permitindo uma ação concorrente das esferas de governo. Alarga-se a contratualidade sociopolítica para incorporar a dimensão de uma cidadania ambiental (SILVA-SÁNCHEZ, 2000).

Com a aprovação da Política Nacional de Meio Ambiente, em 1981, a questão ambiental foi em grande medida fortalecida com a Constituição de 1988, colocando o Brasil no rol dos países preocupados com a internalização dessa problemática no contexto da agenda política e, ao mesmo tempo, legitimando sua participação na arena das negociações internacionais, com ênfase na cooperação multilateral, onde o PPG-7 se tornou um passo importante, mas também nos diversos mecanismos de ajuda financeira para projetos ambientais, sobretudo na escolha para sediar um dos mais significativos eventos mundiais do final do século XX - A Conferência do Rio, em 1992.

Neste sentido, vale fazer uma reflexão sobre o processo de pressão dos diversos segmentos ambientalistas que forjaram a inserção e reconhecimento da temática ambiental como parte constitutiva da cidadania brasileira. Sem dúvida, a conjuntura de preparação para a ECO-92 contribuiu, no plano das relações diplomáticas do Brasil com os países participantes e também no plano interno, na possibilidade de avanços do ambientalismo brasileiro stricto sensu; para a formação de um ambiente favorável às negociações do PPG-7.

Pode-se até mesmo dizer que o PPG-7 não pode ser apreendido na sua dimensão política fora desse contexto, ou seja, como um das questões, certamente com destaque, no amplo debate que envolveu a cúpula dos países na Conferência do Rio. Do ponto de vista das relações internacionais, o Brasil emergia como uma das maiores potências ambientais do planeta, concentrando um banco genético estratégico pela sua biodiversidade, notadamente pelas suas extensas florestas tropicais localizadas na Amazônia.

Apesar das veladas críticas ao governo brasileiro pela condução da política ambiental, ou mais exatamente, pela "incapacidade" de gerenciamento daquilo que é considerado como "patrimônio da humanidade" - que, diga-se de passagem, pode possuir várias interpretações; os países desenvolvidos não poderiam estar alheios à realidade brasileira, a necessidade de estabelecer mecanismos de cooperação na resolução que questões que afetam indistintamente a todos, embora com diferentes rebatimentos sociais e espaciais. 
Do ponto de vista dos fatores políticos internos, a mobilização de um dos segmentos da sociedade civil brasileira em torno de questões ambientais, tornou o campo do ambientalismo uma questão politizada e diretamente ligada à constituição da cidadania, despontando uma coalizão de agentes e instituições com impactos consideráveis sobre a consciência coletiva e como força política marcante nos desdobramentos da ECO-92: o Fórum Brasileiro de ONGs e Movimentos Sociais para o Meio Ambiente e Desenvolvimento. Esta nova configuração política foi produto inequívoco de um processo ainda em construção, da modelagem de uma cidadania alicerçada nos direitos sociais e ambientais de forma abrangente (FERREIRA, 1996).

Entretanto, uma análise do movimento ambientalista brasileiro e sua presença marcante na construção de uma sociedade voltada para a internalização de uma consciência crítica ambiental, não podem abstrair do contexto da política nacional emergente, no caso, a eleição de um presidente - Fernando Collor de Melo, que assumiria um discurso pró-ambientalista como estratégia política para angariar simpatia internacional, credenciando seu governo a postular novos créditos financeiros para a inserção do país na onda modernizante neoliberal. Como bem foi observado, "[...] a apropriação do tema meio ambiente pelo discurso oficial e sua incorporação na estratégia política de Collor apenas dissimularam o fato de que a verdadeira política do governo voltada ao meio ambiente foi uma não-política" (SILVA-SÁNCHEZ, 2000, p. 16).

\section{OS ESTADOS NACIONAIS FRENTE À (IN)SEGURANÇA GLOBAL}

No último quartel do século XX, os processos de globalização enfraqueceram sensivelmente a capacidade de intervenção dos Estados nos limites de seu espaço geográfico, visto que os problemas passaram a adquirir um caráter transnacional, extrapolando territórios e fronteiras, e passaram também a exigir ações coletivas de grupo de países. O período pós-guerra fria condensa mudanças estruturais que vão permitir a aproximação e cooperação multilateral entre os países, considerando a tendência da crescente interdependência entre os Estados-Nação. Castells (1999) mostra que este processo decorreu basicamente de três fatores:

[...] a dissolução, ou afrouxamento dos blocos militares alinhados às duas superpotências; o enorme impacto das novas tecnologias sobre a indústria bélica; e a percepção social do caráter global de grandes desafios que se impõem à humanidade em decorrência do aumento dos conhecimentos e do volume de informações, como é o caso da segurança ambiental" (CASTELLS, 1999, p. 306). 
A globalização do capitalismo e as consequências críticas para o gerenciamento das crises estruturais decorrentes produziram formas e arranjos políticos capazes de lidar com os novos desafios, notadamente instituições supranacionais como o G-7, União Europeia, FMI; que ganham cada vez mais influência nas decisões macro da política mundial. A ameaça ecológica fazia parte do cenário turbulento que poderia comprometer o padrão produtivista ocidental, fundado numa racionalidade econômica, que tem como lógica a necessidade crescente de recursos naturais, a natureza servindo de suporte material no sentido 'utilitarista' para a produção de mercadorias.

A segurança ambiental global deveria ser equacionada como parte indissociável do processo de estabilidade política mundial, criando-se um consenso de que a destruição das florestas tropicais era um aspecto importante da crise do modelo de crescimento global. Os desdobramentos da percepção ecológica dos anos 80 catalisaram uma reflexão nova sobre os desafios que os Estados teriam que enfrentar, considerando a amplitude e gravidade da deterioração da biosfera terrestre.

[...] É, por conseguinte, importante aprofundar esta noção de segurança ambiental, porque ela pode conter os germes de uma nova dimensão importante das relações internacionais, definir opções dos governos, influenciar as relações de conflito e cooperação entre Estados e servir para mobilizar as populações em torno dos objetivos de proteção" (LE PRESTRE, 2000, p. 411).

Todavia, ainda que coagidos por uma razão absolutamente irrefutável, na medida que está em jogo o próprio sistema de poder mundial, o direito soberano dos Estados de participarem ou não de acordos e ações coletivas, estaria sendo respeitado. Porém, do ponto de vista da dinâmica histórica que os empurra para realidade pragmática, os Estados "se encontram cada vez mais emaranhados em uma rede de interdependência e de arranjos regulatórios ou de colaboração, da qual geralmente não se podem livrar" (ZACHER, 2000, p. 86).

Nesta orientação, pode ser compreendida a iniciativa do Chanceler alemão Helmut Kohl, na reunião de cúpula dos países membros do Grupo dos Sete (G-7), em assumir uma posição ecológica progressista, no que diz respeito à preocupação com a perda de florestas e suas consequências imprevisíveis e difusas para o meio ambiente. No interior do conteúdo abrangente que a noção de segurança ambiental pode oferecer, ou seja: [...] a segurança do meio ambiente, a segurança dos indivíduos, a segurança dos Estados e a segurança do sistema internacional (a ordem internacional) [...] (LE PRESTRE, 2000, p. 411), as duas últimas acepções tiveram um peso considerável no raciocínio custo/benefício, adotado certamente como elemento balizador no processo de decisão política, atendendo diretamente aos interesses dos países doadores, tendo em vista a defesa 
e proteção das instituições sociais, políticas e econômicas nacionais, em face das mudanças ecológicas externas.

O interesse em propor um apoio financeiro com intuito de contribuir para a proteção das florestas tropicais brasileiras, não se originou de uma atitude 'generosa' e 'altruísta', como "dádiva” dos ricos do Norte aos pobres do Sul. Apesar dos diferentes níveis de compreensão dos problemas florestais por parte dos países industrializados, teve como pano de fundo um acúmulo de evidências e descobertas científicas, mostrando que a destruição das matas tropicais tinham muito a ver com os países do norte e que os impactos dos desflorestamentos, sobretudo na Amazônia, trariam sérias consequências para as economias desenvolvidas.

Neste sentido, a Amazônia percebida como reserva ecológica do planeta, havia de merecer uma importância particular nesta visão macropolítica. O caráter transnacional das externalidades derivadas dos impactos ambientais, e a expansão da consciência pública, com o surgimento de um movimento ambientalista multissetorial, largamente descentralizado, ampliou consideravelmente a percepção política sobre a importância estratégica de se lutar pela segurança ambiental do planeta, ou seja, para além do sistema internacional formado pelos Estados-Nação. Molda-se agora um sistema internacional policêntrico, onde "O Estado deixa de ser o único sujeito histórico de segurança para participar de um quadro que, em princípio, poderia ser chamado condomínio de segurança. Esse condomínio de segurança seria formado por Estados, movimentos sociais transnacionais e instituições intergovernamentais e supranacionais" (VILLA, 1999, p. 112).

No caso específico do PPG-7, esse condomínio tornou considerável uma diversidade de atores, tais como o grupo dos países mais ricos (G-7), instituições multilaterais de financiamento como o BIRD (Banco Mundial), a União Europeia, o Governo Brasileiro e, sobretudo, uma participação expressiva de ONGs e Redes de ativismo transnacional. A questão da segurança internacional passaria a se enquadrar numa visão mais abrangente, para além da visão tradicional de caráter militar, tornando-se também uma questão pluridimensional, a partir da incorporação de temas emergentes e agendas políticas cada vez mais complexas.

[...] a fórmula conceitual alternativa de segurança internacional parece atender ao surgimento de um tipo ideal de segurança global multidimensional (SGM). Global porque a interdependência e transnacionalização dos novos fenômenos de segurança permite ao conceito abranger significados não apenas localizados, mas planetários. Multidimensional porque não se constitui só de conteúdo estratégico-militar, mas também de outros conteúdos transnacionais, como explosão demográfica, desequilíbrios ecológicos e migrações internacionais, que fazem com que a segurança internacional seja encarada sob diferentes ângulos (VILLA, 1999, p. 99-100). 
A verdade é que a amplitude dos desafios para a superação da crise ecológica requer uma ampla "coalizão" de atores sociais comprometidos com a sustentabilidade planetária, ações multilaterais de cooperação que propiciem atacar as terríveis desigualdades socioambientais, redefinindo espaços de atuação entre Estado, as forças do mercado e a sociedade civil. Todavia, a intenção de financiar projetos visando à proteção do meio ambiente global, já estava presente em discussões anteriores do G-7, tendo em vista a prioridade da temática ambiental na reunião de cúpula dos líderes do G-7, em julho de 1989, na cidade de Paris, reforçando a importância dos processos emergentes derivados da expansão do ambientalismo ocidental, notadamente a partir da década de 1970, no limiar da primeira onda da revolução verde. Neste período, os países do Norte passam a estabelecer formas de regulação ambiental como parte das políticas públicas nacionais, com destaque para o pioneirismo americano, mas não menos relevante, também o surgimento do Partido Verde na Alemanha.

Com efeito, a participação alemã no processo de negociação que culmina na reunião de Houston, longe de ser um fato ocasional, reflete uma crescente consciência da opinião pública alemã em relação à importância das florestas tropicais, visto o alerta de que as florestas na Alemanha estavam desaparecendo, fato que teve repercussão direta na política oficial do governo. A rigor, a questão do meio ambiente se tornou o assunto mais polêmico na política nacional deste país, motivando uma série de artigos da revista Spiegel, em 1981, revelando que a floresta na Alemanha estava altamente danificada, criando-se o slogan da "morte da floresta".

Esta constatação empírica reforça a formulação teórica e metodológica de que o Estado, na arena da política de governança ambiental global, tem um importante papel na negociação de regimes ambientais e acordos multilaterais. As análises de Porter, Brown e Chasek (2000) apontam nesta direção, exemplificando formas diferenciadas de atuação desses atores.

[...] lead state, supporting state, swing state, or veto or blocking state. A lead state has a strong commitment to effective international action on the issue, moves the process of negotiations forward by proposing its own negotiating formula as the basic for an agreement, and attempts to get the support of other state actors. A supporting state speaks in favor of the proposal of a lead state in negociations. A swing state demands a concession to its interests as the price for going along with an agreement, but not a concession that would significantly weaken the regime, such as a slower timetable for a phase-out. A veto or blocking state either opposes a proposed environmental regime outright or tries to weaken it to the point that it cannot be effective [...] (PORTER; BROWN; CHASEK, 2000, p. 35-36).

Não resta dúvida de que a Alemanha liderou efetivamente uma coalizão de países, estes também diretamente interessados nas mudanças ambientais globais, mas com um grau de percepção e mobilização interna ainda muito aquém da 
importância desta problemática na agenda ambiental. A mobilização dos verdes e os impactos decorrentes no processo político-eleitoral, afetando a governabilidade em prol de posturas mais sensíveis ao meio ambiente foi contagiando o governo alemão a adotar um comportamento mais ativo no que concerne a segurança ecológica planetária. A participação alemã foi majoritária também na parte financeira do compromisso assumido com o PPP-7, quase 2/3 do total de recursos.

No conjunto dos países doadores do PPG-7, a Alemanha representava uma posição hegemônica globalista sustentabilista, pela capacidade de coesão de forças internas (tanto de globalistas sustentabilistas como de nacionalistas sustentabilistas), que a diferenciava de outros países (VIOLA, 1993). Os demais países ainda não tinham adquirido uma percepção global da problemática ecológica em comparação ao governo alemão. O Estado brasileiro, apesar da crescente expansão do ambientalismo na década de 1980, ainda não havia incorporado suficientemente uma estratégia de lidar com temas ecológicos globais, notadamente em programas de natureza complexa como o PPG-7, o que ficou refletido nas dificuldades burocráticas e adequação de competência técnica, além das desconfianças de uma parte da comunidade internacional e das Organizações Não Governamentais (ONGs).

Além da ausência de um aparato institucional bem estruturado, tendo em vista as mudanças frequentes nos ministérios e órgãos afins com a questão ambiental, as experiências da diplomacia brasileira nesta matéria, no âmbito da cooperação multilateral, ainda eram reduzidas. A partir da segunda metade da década de 1990, a inserção brasileira torna-me mais propositiva, adotando uma posição de liderança nas negociações sobre mudanças climáticas, mais exatamente sobre o Protocolo de Kioto, onde propõe a criação do MDL, mecanismo que vai favorecer a redução das emissões de gases estufa, através de projetos e experiências que promovam o desenvolvimento sustentável.

\section{CONSIDERAÇÕES FINAIS}

Os desafios de uma interpretação moderna da Amazônia e dos caminhos que contribuam na implementação de vias sustentáveis no seu desenvolvimento passam inevitavelmente pela cooperação internacional, principalmente em função dos benefícios proporcionados pelos ecossistemas regionais amazônicos à dinâmica do desenvolvimento global, notadamente através da sustentabilidade de maior floresta tropical do planeta. O PPG-7 não caiu do céu. Não foi um gesto altruísta de 'bondade universal' do ocidente desenvolvido, mas também não está ligada a nenhuma 'conspiração imperialista'. A partir de uma visão não reducionista, admite-se que seus fundamentos políticos-ideológicos expressam condensações contraditórias de conjunturas anteriores ao seu anúncio pela cúpula do G-7, em 1990, e os processos desencadeados pela Earth Summit, em 1992. 
Com efeito, a emergência e institucionalização desse programa piloto, assumido e integrado ao conjunto das políticas governamentais para a Amazônia, com envolvimento de amplos setores da sociedade civil brasileira, mostraram que a Amazônia está, sim, inserida nas preocupações mundiais, pela importância estratégica de sua rica biodiversidade e pela função estabilizadora que suas florestas oferecem para o clima global. No entanto, as negociações em torno do PPG-7 demonstraram a grande distância entre o discurso e as ações propriamente ditas. De um montante de U\$1,5 bilhão anunciado na Cúpula do G-7 em Houston, foi aprovado somente $\mathrm{U} \$ 250$ milhões para a primeira fase do programa, que começou a ser implementado no início de 1995. Neste sentido, a cooperação internacional, através do PPG-7, coloca-se como mecanismo contraditório e insuficiente, aquém das necessidades de apoio financeiro que a Amazônia requer dos países do Norte, tendo em vista que a canalização desses parcos recursos cumpre a finalidade de compensar minimamente as perdas sofridas pela região via pilhagem de seus recursos naturais pelo capitalismo global.

As questões da biodiversidade e das mudanças climáticas estão na lista dos grandes desafios do século XXI. Esses problemas são de caráter global e demandar soluções negociadas também no plano global. Embora limitada, e até mesmo marginalizada, sobretudo em razão da postura centralizadora e autoritária de diversos setores da burocracia brasileira, a participação da sociedade civil, representada predominantemente pelas ONGs, cumpriu um papel fundamental na conformação de um espaço público democrático transnacional. Essa participação ampliou a esfera pública nas questões envolvendo a Amazônia e seu futuro, permitindo, no plano da legitimidade política, atender os anseios e interesses mais diretos da população regional envolvida.

A Amazônia tornou-se objeto de preocupação política do governo brasileiro, decisivamente pela pressão externa, ou seja, ao invés de soberanamente tomar iniciativa em termos de políticas eficazes e de longo prazo para a região, o governo brasileiro age de forma reativa às demandas exógenas. Foi fundamentalmente através da pressão internacional que o governo redefiniu a política para a Amazônia, tentando sedimentar estruturas mais eficientes no combate ao desmatamento e fiscalização. A contribuição da região à governança global não diz respeito apenas ao seu importante papel nas mudanças climáticas e reservas de sociobiodiversidade que abriga, mas essencialmente por apontar em direção a um novo patamar civilizatório, fundamentado no aproveitamento sustentável dos recursos renováveis.

A busca de alternativas e um futuro sustentável para a Amazônia não ocorrerão sem uma ampla articulação de forças nas diferentes esferas de espaço, território, poder e identidades. A contemporaneidade reflete avanços em direção à constituição de padrões de governança mais democráticos e policêntricos. 


\section{REFERÊNCIAS}

AB'SABER, A. Domínios de natureza no Brasil: ordens de criticidade. O caso da Amazônia. In: VELlosO, J. P. R. (Org.). A ecologia e o novo padrão de desenvolvimento no Brasil. São Paulo: Nobel, 1992.

ARNT, R.; SCHWARTZMAN, S. Um artifício orgânico: transição na Amazônia e ambientalismo. Rio de Janeiro: Rocco, 1992.

BENCHIMOL, S. Amazônia: a guerra na floresta. Rio de Janeiro: Civilização Brasileira, 1992.

CAPOBIANCO, J. P. R. Biomas brasileiros. In: CAMARGO, A.; CAPOBIANCO, J. P. R.; OLIVEIRA, J. A. P. (Orgs.). Meio ambiente Brasil: avanços e obstáculos pós-Rio92. São Paulo: Estação Liberdade; Instituto Socioambiental; Rio de Janeiro: Fundação Getúlio Vargas, 2002.

CASTELLS, M. A sociedade em rede. A era da informação: economia, sociedade e cultura. v. 1). Tradução de Roneide Venâncio Majer. São Paulo: Paz e Terra, 1999.

CAUBET, C. G. As várias cidadanias da Constituição de 1988. Ciências sociais hoje. São Paulo: Vértice, Revista dos Tribunais; ANPOCS, 1989.

FEARNSIDE, P. Serviços ambientais como estratégia para o desenvolvimento sustentável na Amazônia rural. In: CAVALCANTI, C. (Org.). Meio ambiente, desenvolvimento e políticas de governo: bases para construção de uma sociedade sustentável no Brasil (levando em conta a natureza). Olinda: Fundação Joaquim Nabuco, 1996.

FERREIRA, L. C. Os ambientalistas, os direitos sociais e o universo da cidadania. In: FERREIRA, L. C.; VIOLA, E. (Orgs.). Incertezas de sustentabilidade na globalização. Campinas: UNICAMP, 1996.

GOLDEMBERG, J. A Amazônia e o efeito estufa, simpósio Amazônia: fatos, problemas e soluções. São Paulo: USP, 1989.

GONÇALVES, C. W. P. Amazônia, Amazônias. São Paulo: Contexto, 2001.

Os movimentos sociais diante da reorganização societária em curso. In: VIANA, G.; SILVA, M.; DINIZ, N. (Orgs.). O desafio da sustentabilidade: um debate socioambiental no Brasil. São Paulo: Fundação Perseu Abramo, 2001a.

KITAMURA, P. C. A Amazônia e o desenvolvimento sustentável. Brasília: EMBRAPA, 1994.

Amazônia: produtos e serviços naturais e as perspectivas para o desenvolvimento sustentável regional. In: ROMEIRO, A. R.; REYDON, B. P; 
LEONARDI, M. L. A. (Orgs.). Economia do Meio Ambiente: teoria, políticas e a gestão de espaços regionais. Campinas: UNICAMP/IE, 1997.

LEITE, M. A floresta amazônica. São Paulo: Publifolha, 2001. (Folha explica).

LE PRESTRE, P. Ecopolítica internacional. São Paulo: SENAC São Paulo, 2000.

LIPIETZ, A. Cercando os bens comuns globais: negociações sobre o meio ambiente global em uma abordagem do conflito norte/sul. In: CASTRO, E.; PINTON, F. (Orgs.). Faces do trópico úmido: conceitos e novas questões sobre desenvolvimento e meio ambiente. Belém: Cejup; UFPA/NAEA, 1997.

NOSSA COMUNIDADE GLOBAL. O relatório da Comissão sobre Governança Global. Rio de Janeiro: Fundação Getúlio Vargas, 1996.

OLIVEIRA, F. A reconquista da Amazônia. In: D’INCAO, M. A.; SILVEIRA, I. M. (Orgs.). Amazônia e a crise da modernização. Belém: Museu Paraense Emílio Goeldi, 1994.

PORTER, G.; BROWN J. W.; CHASEK, P. S. Global environmental politics. Colorado: Westview Press, 2000.

SCHUBART, H. A Amazônia e os temas ecológicos globais: mitos e realidade. Brasília: Instituto Sociedade, População e Natureza, 1991. (Documento de trabalho n. 6).

SILVA, M. C. Metamorfoses da Amazônia. 1997. Tese (Doutorado) - Unicamp, Campinas, 1997.

SILVA-SANCHEZ, S. S. Cidadania ambiental: novos direitos no Brasil. São Paulo: Humanitas/FFLCH/USP, 2000.

STROH, P. Y. Sustentabilidade da biodiversidade florestal da Amazônia: um desafio complexo de construção da democracia participativa. Brasília, 1998. Mimeo. VILLA, R. A. D. A segurança global multidimensional. Revista de Cultura e Política. Lua Nova, São Paulo, n. 46, 1999.

VIOLA, E. A expansão do ambientalismo multissetorial e a globalização da ordem mundial, 1985-1992. Brasília: Instituto Sociedade, População e Natureza, 1993. (Documento de trabalho, n.6).

ZACHER, M. Os pilares em ruína do templo de Vestfália: implicações para a governança e a ordem mundial. In: ROSENAU, J.; CZEMPIEL, E.-O. (Orgs.). Governança sem governo. Tradução de Sérgio Bath. Brasília: Editora Universidade de Brasília; São Paulo: Imprensa Oficial do Estado, 2000. 